International Journal of Vaccines and Research (IJVR)

ISSN 2572-7427

\title{
Molecular Mechanisms of HPV Infection in the Lower Genital Tract
}

G Androutsopoulos ${ }^{1}$, G Adonakis ${ }^{1}$, G Decavalas $^{1}$

Editorial

${ }^{1}$ Department of Obstetrics and Gynecology, University of Patras, Medical School, Rion, Greece.

*Corresponding Author:

G Androutsopoulos MD,

Lecturer, Department of Obstetrics and Gynecology,

University of Patras, Medical School,

Rion 26504, Greece.

Tel: +306974088092

E-mail: androutsopoulos@upatras.gr

Received: August 18, 2014

Published: September 29, 2014

Citation: G Androutsopoulos, G Adonakis, G Decavalas (2014) Molecular Mechanisms of HPV Infection in the Lower Genital Tract 1:101 doi: http://dx.doi.org/10.19070/2572-7427-140001e

Copyright: G Androutsopoulos MD ${ }^{\circ}$ 2014. This is an open-access article distributed under the terms of the Creative Commons Attribution License, which permits unrestricted use, distribution and reproduction in any medium, provided the original author and source are credited.

Human papillomaviruses (HPV) are small, non-enveloped viruses.[1] They contain circular double-stranded DNA within an icosahedral capsid.[2] Despite their small size, they have very complex molecular biology.[3] They have 2 structural proteins (L1 and L2) that compose the viral capsid.[3-5] Also, they have 3 oncogenes (E5, E6 and E7) that modulate the transformation process. $[3,4]$ Moreover, they have 2 regulatory proteins (E1 and E2) that modulate transcription and replication. $[3,4]$

The infectious cycle of HPV is conducted entirely within a fully differentiated squamous epithelium.[1] HPV infection requires that virus particles gain access to the epithelial basal layer and enter the dividing basal cells. [2] It is necessary a micro-abrasion of the epithelial surface, that removes the epithelium but keeps the basement membrane intact.[1] The thinner and more fragile metaplastic epithelium may be more susceptible to the microabrasion process and thus to HPV infection.[1] HPV infection is very common in young sexually active women.[1]

The viral L1 protein binds to the exposed basement membrane of probably via heparan sulphate proteoglycans (HSPGs) [primary receptor].[1,6-8] This binding results in conformational changes and distortion of the virus capsid.[1,6-8] This distortion exposes the viral L2 protein to cleavage by furin or by proprotein convertase 5/6.[1,6-10] This cleavage site is absolutely conserved among all HPV types[1,9-11] Proteolytic cleavage by furin, is essential for successful infection. [6,8-11]

After cleavage, the viral L2 protein binds to the cell surface and this triggers a second conformational change in the virus capsid. $[1,6,11]$ This conformational change either exposes the binding site for the secondary receptor on the viral L1 protein or it lowers the affinity for the primary receptor. $[1,6,8,10,11]$ Then viral L1 protein binds to $\alpha 6$ integrin on the cell surface [secondary receptor] and triggers receptor mediated endocytosis of HPV. $[1,6,7,10,11]$

Most HPV types generally use clathrin dependent endocytic pathway.[6,8,10-13] However, some HPV types use alternative endocytic pathways (caveolae dependent endocytic pathway or clathrin and caveolae independent endocytic pathway). $[6,8,10,11,14,15]$

HPV has the ability to avoid lysosomal degradation.[13-16] It can escape from the endosomes to the cytosol, with fusion independent mechanisms. [16] The decrease of $\mathrm{pH}$ in early endosomes results in conformational changes of HPV capsid and trigger the endosomal escape of the HPV genome or the complex of HPV genome and L2 protein. [13,17]

Viral L2 protein is required for egress of viral genomes from endosomes, but not for initial uptake and uncoating. $[8,18]$ Moreover viral L2 protein interact with the microtubule network via the motor protein dynein. $[10,18]$ This interaction mediates the transport of the complex of HPV genome and L2 protein along microtubules towards the nucleus.[10,18]

Moreover, viral L2 protein contains nuclear localization signals (NLSs).[19] Those NLSs interact with a network of karyopherins and mediate nuclear entry of HPV genome and L2 protein via several pathways (karyopherin $\alpha 2 \beta 1$ heterodimers, karyopherin $\beta 2$ and karyopherin $\beta 3)$. $[19,20]$ Binding of Ran-GTP to the karyopherin $\beta$ causes dissociation of the import complexes and release the complex of HPV genome and L2 protein inside the nucleus.[19-21] Finally the complex of HPV genome and L2 protein enters the nucleus.10 18 Then it localizes at punctate nuclear regions known as PML nuclear bodies (PML-NBs), promyelotic oncogenic domains (PODs) or nuclear domain 10 (ND10).[22-24] Those nuclear structures are responsible for transcriptional processes. $[23,25,26]$ HPV transcription and replication occur in association with PML-NBs. [10,23,27,28]

During latent infection, HPV maintains its genome as autonomous replicating episomes in the proliferating basal cells of the squamous epithelium.[29,30]

It is obvious that HPV has very complex molecular biology. Despite significant advances regarding molecular biology of HPV infection, there are many questions to be answered. Moreover, the better understanding of molecular mechanisms of HPV infection is very important for further development of new generation HPV vaccines. 


\section{References}

[1]. Stanley M ( 2009) HPV genital tract infection. molecular pathogenesis. CME 14:30-35.

[2]. Doorbar J (2006) Molecular biology of human papillomavirus infection and cervical cancer. Clin Sci (Lond) 110(5):525-41.

[3]. de Villiers E, Fauquet C, Broker T, Bernard H, zur Hausen H (2004) Classification of papillomaviruses. Virology 324(1):17-27.

[4]. Munger K, Howley P (2002) Human papillomavirus immortalization and transformation functions. Virus Res 89(2):213-28.

[5]. Modis Y, Trus B, Harrison S (2002) Atomic model of the papillomavirus capsid. EMBO J 21(18):4754-62.

[6]. Sapp M, Day P (2002) Structure, attachment and entry of polyoma- and papillomaviruses. Virology 384(2):400-9.

[7]. Raff A, Woodham A, Raff L, Skeate J, Yan L, et al (2013) The evolving field of human papillomavirus receptor research: a review of binding and entry. J Virol 87(11):6062-72.

[8]. Sapp M, Bienkowska-Haba M (2009) Viral entry mechanisms: human papillomavirus and a long journey from extracellular matrix to the nucleus. FEBS J 276(24):7206-16.

[9]. Richards R, Lowy D, Schiller J, Day P (2006) Cleavage of the papillomavirus minor capsid protein, L2, at a furin consensus site is necessary for infection.Proc Natl Acad Sci USA. 103(5):1522-7.

[10]. Schiller J, Day P, Kines R (2010) Current understanding of the mechanism of HPV infection. Gynecol Oncol 118(1 Suppl):S12-7.

[11]. Horvath C, Boulet G, Renoux V, Delvenne P, Bogers J (2010) Mechanisms of cell entry by human papillomaviruses: an overview. Virol J 7(11):11.

[12]. Pelkmans L, Helenius A (2003) Insider information: what viruses tell us about endocytosis. Curr Opin Cell Biol 15(4):414-22.

[13]. Day P, Lowy D, Schiller J (2003) Papillomaviruses infect cells via a clathrindependent pathway. Virology 307(1):1-11.

[14]. Bousarghin L, Touze A, Sizaret P, Coursaget P (2003) Human papillomavirus types 16,31 , and 58 use different endocytosis pathways to enter cells. J Virol 77(6):3846-50.

[15]. Spoden G, Freitag K, Husmann M, Boller K, Sapp M, et al (2008) Clathrin-and caveolin-independent entry of human papillomavirus type 16-involvement of tetraspanin-enriched microdomains (TEMs). PLoS One 3(10):e3313.
[16]. Mudhakir D, Harashima H (2009) Learning from the viral journey: how to enter cells and how to overcome intracellular barriers to reach the nucleus. AAPS J 11(1):65-77.

[17]. Letian T, Tianyu Z (2010) Cellular receptor binding and entry of human papillomavirus. Virol J 7(2):2.

[18]. Kamper N, Day P, Nowak T, Selinka H, Florin L, et al (2006) A membranedestabilizing peptide in capsid protein $\mathrm{L} 2$ is required for egress of papillomavirus genomes from endosomes. J Virol 80(2):759-68.

[19]. Darshan M, Lucchi J, Harding E, Moroianu J (2004) The 12 minor capsid protein of human papillomavirus type 16 interacts with a network of nuclear import receptors. J Virol 78(22):12179-88.

[20]. Le Roux L, Moroianu J (2003) Nuclear entry of high-risk human papillomavirus type 16 E6 oncoprotein occurs via several pathways. J Virol 77(4):2330-7.

[21]. Fried H, Kutay U (2003) Nucleocytoplasmic transport: taking an inventory. Cell Mol Life Sci 60(8):1659-88.

[22]. Day P, Roden R, Lowy D, Schiller J (1998) The papillomavirus minor capsid protein, L2, induces localization of the major capsid protein, L1, and the viral transcription/replication protein, E2, to PML oncogenic domains. J Virol 72(1):142-50.

[23]. Florin L, Sapp M, Spoden G (2012) Host-cell factors involved in papillomavirus entry. Med Microbiol Immunol 201(4):437-48.

[24]. Florin L, Schafer F, Sotlar K, Streeck R, Sapp M (2002) Reorganization of nuclear domain 10 induced by papillomavirus capsid protein 12. Virology 295(1):97-107.

[25]. Lallemand-Breitenbach V, de The H (2010) PML nuclear bodies. Cold Spring Harb Perspect Biol;2(5):a000661.

[26]. Maul G (1998) Nuclear domain 10, the site of DNA virus transcription and replication. Bioessays 20(8):660-7.

[27]. Swindle C, Zou N, Van Tine B, Shaw G, Engler J, et al (1999) Human papillomavirus DNA replication compartments in a transient DNA replication system. J Virol 73(2):1001-9.

[28]. Day P, Baker C, Lowy D, Schiller J (2004) Establishment of papillomavirus infection is enhanced by promyelocytic leukemia protein (PML) expression. Proc Natl Acad Sci USA 101(39):14252-7.

[29]. You J (2010) Papillomavirus interaction with cellular chromatin. Biochim Biophys Acta 1799(3-4):192-9.

[30]. Doorbar J (2005) The papillomavirus life cycle. J Clin Virol 32 Suppl $1: S 7-15$. 